\title{
Use of intraductal cholangioscopy devices to retrieve migrated pancreatic stents
}

The incidence of proximal pancreatic stent migration is unknown, though early studies report up to $5 \%$, with recently reported success rates of $<80 \%$ for stent retrieval using conventional techniques [1]. Stent retrieval remains challenging owing to characteristically small pancreatic duct diameters, strictures, tortuous distal pancreatic duct course, stent location proximal to the genu, and small-caliber stents.

Novel retrieval techniques for proximally migrated pancreatic stents have included pancreatoscopy to achieve guidewire cannulation of the stent lumen [2,3] or facilitate retrieval using SpyByte forceps (Boston Scientific, Marlborough, Massachusetts, USA), though duct diameter must be large enough to accommodate a SpyScope for such techniques. For ducts of small or normal diameter, proximally migrated stents can be cannulated with a guidewire, over which mini-snares can be passed to retrieve the stent $[4,5]$.

We describe two cases in which a Spysnare and SpyBasket, used without the accompanying SpyScope, were used to retrieve proximally migrated pancreatic stents in normal diameter ducts ( Video 1).

A 52-year-old woman was referred for retrieval of a proximally migrated prophylactic 5-Fr pancreatic stent. On pancreatography the stent's distal tip was proximal to the genu with the proximal tip in the body or tail. A pancreatic sphincterotomy was performed using a papillotome over a guidewire. The stent lumen was cannulated with a 0.035 -inch guidewire, over which a SpySnare was advanced to capture and retrieve the stent. A 44-year-old woman with history of relapsing pancreatitis presented for repeat endotherapy. The previously placed pancreatic stent was not visible endoscopi-

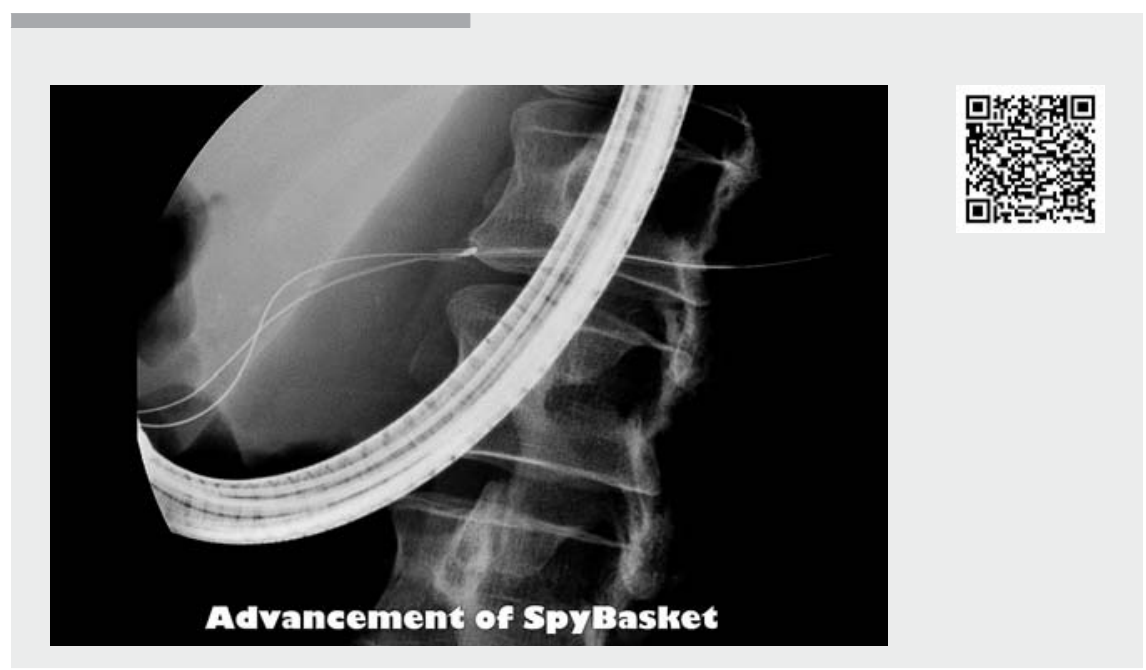

Video 1 Use of SpyScope devices to retrieve migrated pancreatic stents.

cally, and stent migration proximal to the genu was confirmed on fluoroscopy. A 4-mm balloon was used to dilate a distal pancreatic duct stricture. The stent lumen was cannulated with a curved 0.035-inch guidewire. Despite previous unsuccessful retrieval attempts using SpySnare, the pancreatic stent was successfully captured and retrieved using SpyBasket.

Endoscopy_UCTN_Code_CPL_1AK_2AI

\section{Competing interests}

None

The authors

Sheila Rastegari, Cassandra Craig, Elizabeth John, Prashant Kedia, Paul Tarnasky

Methodist Dallas Medical Center, Dallas, Texas, United States

\section{Corresponding author}

\section{Cassandra Craig, MD}

Methodist Dallas Medical Center,

Department of Gastroenterology, 1441

North Beckley Avenue, Dallas, Texas 75203 , United States

Fax: +1-214-947-6701

cassandracraig@mhd.com

\section{References}

[1] Price LH, Brandabur J], Kozarek RA et al. Good stents gone bad: endoscopic treatment of proximally migrated pancreatic duct stents. Gastrointest Endosc 2009; 70: 174-179

[2] Yao W, Huang Y, Chang H et al. Endoscopic retrieval of a migrated pancreatic stent under direct pancreatoscopy by use of a "snare over in-stent wire guide" method. VideoGIE 2018; 3: 272-274

[3] Girotra M, Raghavapuram S, Tharian B. Successful removal of deeply migrated pancreatic stent using biliary dilation balloon and the new single-operator digital cholangioscope. Gastrointest Endosc 2016; 84: 10611062 
[4] Yoon LY, Moon JH, Choi H] et al. Wire-guided endoscopic snare retrieval of proximally migrated pancreatic stents after endoscopic papillectomy for ampullary adenoma. Gut Liver 2011; 5: 532-535

[5] Liao YS, Zhao Q, Fan Y et al. Proximal migration of a 5 French pancreatic stent during bile stone extraction: a successful retrieval using mini-snare. Niger J Clin Pract 2014; 17: 384386
Bibliography

DOI https://doi.org/10.1055/a-1066-4453

Published online: 13.12.2019

Endoscopy 2020; 52: E202-E203

(c) Georg Thieme Verlag KG

Stuttgart · New York

ISSN 0013-726X

\section{ENDOSCOPY E-VIDEOS}

https:/|eref.thieme.de/e-videos

口回 Endoscopy E-Videos is a free 然故 access online section, reporting 靣: on interesting cases and new techniques in gastroenterological endoscopy. All papers include a high quality video and all contributions are freely accessible online.

This section has its own submission website at

https://mc.manuscriptcentral.com/e-videos 